\title{
DO CONTRABANDO AO CONSULADO: A ATUAÇÃO DO ESTADUNIDENSE JOHN SMITH GILLMER NA BAHIA (1826-1862)
}

From contraband to the consulate: John Smith Gillmer's operation in Bahia (1826-1862) 


\title{
RESUMO
}

Neste artigo analisamos a trajetória do negociante estadunidense John Smith Gillmer na Bahia, de 1826 (ano em que localizamos o primeiro registro de sua atuação na província) até 1862 (ano de seu falecimento). Com base, principalmente, em revisão bibliográfica e notícias de periódicos, procuramos demonstrar que, na contramão das perseguições realizadas pelo governo dos Estados Unidos contra cidadãos envolvidos no contrabando negreiro para o Brasil, determinados agentes, como John Smith Gillmer, conseguiram alcançar grande projeção política, sendo nomeados, inclusive, para cargos diplomáticos, a despeito da sua sabida participação no crime. O trabalho está dividido em três seções: na primeira, abordamos a inserção de John Smith Gillmer na economia brasileira; na segunda, tratamos sobre sua participação no contrabando negreiro para a Bahia; e, na terceira, versamos sobre sua alçada ao posto de Cônsul dos Estados Unidos na província. Assim, buscamos evidenciar aspectos do complexo processo que envolveu a participação de estadunidenses, bem como a intervenção do governo dos Estados Unidos, no contrabando negreiro para o Brasil.

\section{PALAVRAS-CHAVE}

Tráfico de escravos. Brasil. Estados Unidos da América.

\begin{abstract}
In this article, we analyse the trajectory of American trader John Smith Gillmer in Bahia, from 1826 (year in which we located the first record of his operation in the province) until 1862 (year of his death). Based mainly on bibliographic review and news from periodicals, we seek to demonstrate that, in spite of the persecutions carried out by the United States government against citizens involved in slave trade to Brazil, certain agents, such as John Smith Gillmer, were able to achieve political projection, being even appointed to diplomatic posts, despite his known participation in the crime. The work is divided into three sections: in the first, we approach the insertion of John Smith Gillmer in the Brazilian economy; in the second, we deal with his participation in the slave trade to Bahia; and, in the third, we discuss his appointment as Consul of the United States in the province. Thus, we seek to highlight aspects of the complex process that involved the participation of Americans, as well as the intervention of the United States government, in the transatlantic slave trade to Brazil.
\end{abstract}

\section{KEYWORDS}

Slave trade. Brazil. United States of America. 
comércio transatlântico de escravos para os Estados Unidos foi definitivamente abolido, e a participação de cidadãos estadunidenses no tráfico para outros países foi proibida, por lei aprovada em 1807 e implementada em 1808. Apesar disto, de um lado, continuou existindo contrabando residual para o país até a década de 1820 e, de outro, estadunidenses atuaram no tráfico legal e ilegal para outras localidades, principalmente Brasil e Cuba, como contrabandistas ou colaboradores, até a segunda metade do século XIX (MARQUES, 2016).

Durante o período em que vigorou o contrabando negreiro para o Brasil, do início da década de 1830 até meados da década de 1850, por exemplo, foi recorrente o emprego de navios construídos nos Estados Unidos, assim como da bandeira do país neste crime. Ao contrário daqueles sob bandeira portuguesa, espanhola e brasileira, os navios sob bandeira estadunidense permaneceram legalmente protegidos das inspeções da marinha britânica durante todo o período em que o tráfico ilegal para o Brasil esteve ativo, ${ }^{1}$ o que os tornava extremamente valorizados entre os contrabandistas (CONRAD, 1985; VERGER, 1987; GRADEN, 2007; HORNE, 2010; MARQUES, 2016).

Outro fator que contribuiu para o largo emprego destas naves no contrabando foi sua capacidade de navegação. Isto porque a indústria naval estadunidense se especializou na fabricação de veleiros e também de algumas embarcações a vapor altamente velozes, próprios para serem empregados no crime (CONRAD, 1985; GRADEN, 2007; HORNE, 2010; MARQUES, 2016). Segundo Leonardo Marques, é possível estimar que navios construídos nos Estados Unidos foram responsáveis por realizar 58,2\% das viagens negreiras para o Brasil, no período de 1831 a 1850 . O segundo lugar foi ocupado pelos construídos dentro do próprio Império brasileiro, um total de 15,4\% (MARQUES, 2016, p. 143).

O acesso a embarcações e à bandeira dos Estados Unidos por negociantes que atuavam no tráfico ilegal para o Brasil era garantido por meio de intermediários estadunidenses. Todo o processo, desde a fabricação das naves, sua equipagem para uma viagem negreira, o translado para o país importador, o fornecimento de documentação e sua venda ou fretamento para os traficantes ilegais, até a realização da expedição em si, movimentava uma ampla rede que exigia participação tanto direta quanto indireta daqueles indivíduos, inclusive de autoridades diplomáticas. Estas etapas, quando concluídas com sucesso, resultavam na geração de grandes lucros, o que deve ter-se tornado o principal atrativo para o crime. Mas, os sujeitos que agiam neste negócio também estavam suscetíveis a embaraços - como a deposição de cargos, no caso de autoridades, e mesmo eventuais prisões, para pessoas ordinárias (WRIGHT, 1978, p. 245-246; CONRAD, 1985, p. 164; GRADEN, 2007, p. 28; HORNE, 2010, p. 87; MARQUES, 2016, p. 160).

Embora a participação dos Estados Unidos no contrabando negreiro para o Brasil tenha sido (e venha sendo) abordada pela historiografia, ${ }^{2}$ com exceção de pesquisas que têm como enfoque o Rio de Janeiro, ${ }^{3}$ quem foram estes indivíduos e qual a dinâmica

\footnotetext{
${ }^{1}$ Apenas em 1862 os Estados Unidos firmaram tratado com a Inglaterra concedendo direito de busca em embarcações suspeitas de serem empregadas no tráfico transatlântico (MARQUES, 2016, p. 244). ${ }^{2}$ A participação dos Estados Unidos no contrabando negreiro para o Brasil foi mencionada em obras como as de Robert Conrad (1985), Dale Graden (2007) e Gerald Horne (2010). Mais recentemente, Leonardo Marques (2016) tem desenvolvido estudos dedicados exclusivamente a esta temática.

${ }^{3}$ Para o Rio de Janeiro, os trabalhos de Alan Ribeiro (2014) e João Marcos Mesquita (2019) abordam
} 
da sua cooperação com o crime ainda carecem de estudos mais aprofundados. Assim, buscando contribuir para o preenchimento desta lacuna, neste artigo, analisamos a atuação do estadunidense John Smith Gillmer na Bahia. Gillmer era sócio da firma que carregava seu nome e que foi, na década de 1840, a principal consignatária de navios negreiros na província (o segundo maior porto de desembarques de cativos provenientes do contrabando transatlântico no Brasil). Iniciamos o texto versando sobre a inserção de John Smith Gillmer na economia brasileira, para, em seguida, tratar sobre sua participação no tráfico ilegal. Por fim, abordamos um aspecto bastante peculiar da sua trajetória, a sua alçada ao cargo de Cônsul dos Estados Unidos na Bahia.

\section{INSERÇÃO NA ECONOMIA BRASILEIRA}

No início do século XIX, Brasil e Estados Unidos mantinham estreita relação comercial, principalmente impulsionada, de um lado, pelo aumento das importações de farinha de trigo estadunidense e, de outro, pelas exportações do café brasileiro. Ao longo da primeira metade do século XIX, a intensificação destes vínculos motivou a vinda de comerciantes do país norte-americano para o Brasil, seja para atuar como representantes de firmas ou de interesses próprios (HORNE, 2010, p. 18; ROOD, 2014, p. 32).

John Smith Gillmer esteve neste fluxo de migrantes entre o norte e o sul da América. As primeiras informações sobre sua presença na Bahia, relativas à década de 1820, indicam que foi por meio daquela atividade que ele se inseriu na economia brasileira (ODIN, 24 jul. 1826). Natural da Filadélfia, ele comerciava com a Bahia desde, pelo menos, 1826 e estava estabelecido nesta província desde, pelo menos, 1829, quando aparece nela registrado como negociante estrangeiro (OLIVEIRA, 1985, p. 69; NEGOCIANTES..., 1829, p. 198). É muito provável que ele tenha feito parte das primeiras levas de indivíduos que vieram de sua cidade natal para o Brasil, pois linhas de transporte transatlântico ligando as duas regiões haviam sido inauguradas em 1821, por negociantes da Filadélfia interessados pelo comércio com o sul do continente (LAURIE, 1980, p. 8).

Desde o princípio, a atuação de Gillmer na Bahia foi permeada por eventos controversos. Nos anos de 1826 e 1828, navios consignados a sociedades por ele lideradas foram alvo de ações por parte de autoridades baianas, estimulando contendas entre estas e o cônsul dos Estados Unidos na província, Woodbrigde Odin. No primeiro caso, em 1826, o brigue estadunidense Corporal Trim, carregado com farinha de trigo e outras mercadorias não especificadas, foi impedido de ingressar na Alfândega da Bahia por não conter o certificado do cônsul brasileiro nos Estados Unidos, Francisco Joaquim de Lima, anexado ao manifesto da carga (ODIN, 24 jul. 1826). A presença do certificado era um aspecto de suma importância, porque assegurava a autenticidade das informações apresentadas no manifesto. No segundo episódio, ocorrido dois anos mais tarde, em 1828, o navio Rasselas foi abordado por soldados baianos no porto de Salvador, por motivos que desconhecemos (ODIN, 3 mar. 1828).

A ocorrência destes dois incidentes, em um espaço de tempo relativamente curto, levanta indícios de que, desde a década de 1820, John Smith Gillmer já praticava

a atuação da firma estadunidense Maxwell Wright e Co. e um de seus associados, Manoel Pinto da Fonseca, no contrabando negreiro. 
atividades ilícitas. Afinal, por que o brigue Corporal Trim não trouxe consigo o certificado da carga? O que motivou a abordagem do Rasselas pelos soldados baianos?

$\mathrm{Na}$ década de 1830, as atividades do negociante se expandiram. Primeiro, ele começou a realizar transporte de cabotagem entre a Bahia e o Rio de Janeiro (NOTÍCIAS..., 1833, p. 4). Posteriormente, passou a negociar também no Rio da Prata (NOTÍCIAS..., 1835, p. 4). Embora não tenha sido possível aprofundar como foi sua atuação nesta localidade, isso indica que ele estava inserido em uma ampla rede comercial, que operava em diferentes partes do continente americano. Vale mencionar que o Rio da Prata era outra importante área importadora de mercadorias estadunidenses no período (HORNE, 2010, p. 10; PRADO, 2017), o que deve ter favorecido a penetração de Gillmer na região.

Já na segunda metade da década de 1830, a firma John Smith Gillmer e Cia., sediada na Bahia e consignatária das embarcações Corporal Trim e Rasselas, já mencionadas, foi extinta e, em 1838, o negociante estabeleceu uma casa comercial no Rio de Janeiro sob a firma Phelps e Gillmer (ANNUNCIOS, 1838, p. 3). ${ }^{4}$ Esta sociedade atuava principalmente importando farinha de trigo das cidades de Baltimore (Maryland), Filadélfia (Pensilvânia) e Richmond (Virgínia) nos Estados Unidos, para o Rio de Janeiro (havendo também indícios da reexportação da farinha para Pernambuco) (MOVIMENTO..., 1839a, p. 4; MOVIMENTO..., 1839b, p. 4; PARTE..., 1839a, p. 4; PARTE..., 1839c, p. 4;); e exportando café do Rio de Janeiro para a cidade natal de Gillmer, a Filadélfia, e para Mobile (México) (PARTE..., 1838, p. 3; PARTE..., 1839b, p. 3).

Entretanto, a duração da sociedade entre Phelps e Gillmer foi curta. A empresa foi dissolvida em 31 de dezembro de 1839, menos de dois anos após o início de seu funcionamento. Com a sua extinção, Gillmer aparentemente deixou de importar farinha de trigo para o Rio de Janeiro, mas permaneceu operando de maneira individual na casa comercial da extinta firma, exportando café para os Estados Unidos por, pelo menos, mais um ano, até 1840, quando supomos que esta atividade também foi encerrada. A partir de 1840, a empresa de John Smith Gillmer passou a atuar no Rio de Janeiro, principalmente, com transporte de cargas e passageiros para a Bahia (AVISOS..., 1840, p. 3).

Em janeiro de 1841, após tentativa de se fixar na Corte, John Smith Gillmer retornou à Bahia, voltando a gerir seu negócio de transporte de cargas e passageiros a partir da província (MOVIMENTO..., 1841b, p. 4; AVISOS..., 1841, p. 4). Embora sua empreitada no Rio de Janeiro tenha sido, aparentemente, infrutífera, não podemos negligenciar os efeitos positivos que sua estadia naquela praça comercial pode ter tido sobre seus negócios. Durante o período em que ali esteve, Gillmer deve ter ampliado sua rede e se fortalecido economicamente. Ratifica essa hipótese o grande salto que seus negócios alcançaram a partir do ano de 1843. Desde então, ele voltou a realizar importações, em um intenso movimento comercial de diferentes mercadorias (como sal, óleo de baleia ou "azeite de peixe", carvão mineral, além da já mencionada farinha de trigo, entre outros gêneros) que envolvia o Brasil, o Rio da Prata, os Estados Unidos, a Europa e a África (DECLARAÇÕES, 1843, p. 4; MOVIMENTO..., 1843a, p. 4; MOVIMENTO..., 1843b, p. 4; MOVIMENTO, 1843d, p. 4). Além disso, ainda no ano

\footnotetext{
${ }^{4}$ Não localizamos documentos que explicitem quem era o sócio ou os sócios de Gillmer na firma. A análise das fontes leva a crer que se tratava do também estadunidense Henry Phelps, sobre quem não conseguimos encontrar mais informações (MOVIMENTO..., 1839c, p. 4).
} 
de 1843, ele foi eleito (e reeleito nos anos de 1844 e 1845) para compor a junta diretora da Associação Comercial da Bahia, instituição na qual teve uma importante inserção (PARTE..., 1843, p. 3; PARTE..., 1844, p. 4; BAHIA, 1845, p. 2).

Uma das razões que contribuíram para isso deve ter sido seu envolvimento no tráfico ilegal, tanto fretando e vendendo embarcações para contrabandistas, quanto organizando expedições negreiras.

\section{ATUAÇÃO NO CONTRABANDO NEGREIRO}

O uso da bandeira e de navios construídos nos Estados Unidos no tráfico e no contrabando negreiro para a Bahia era recorrente desde, pelo menos, a década de 1820. Ainda em 1826, o cônsul dos Estados Unidos, Woodbridge Odin, afirmara que a maioria dos vasos empregados no tráfico transatlântico na província era de fabricação estadunidense (CONRAD, 1985, p. 149). A declaração de Odin não deixa de nos fazer rememorar os incidentes de 1826 e 1828 ocorridos com o Corporal Trim e, principalmente, o Rasselas, consignados a John Smith Gillmer e Cia., no porto de Salvador. Afinal, seria o Rasselas um navio negreiro?

O engajamento de cidadãos dos Estados Unidos no tráfico ilegal para o Brasil se intensificou a partir da década de 1840. Isso se deve ao fato de que, no final da década de 1830 e em meados da década de 1840, foram aprovadas no parlamento britânico duas leis, o Bill Palmertson (1839) e o Bill Aberdeen (1845), que concediam o direito de captura de navios suspeitos de serem empregados no contrabando negreiro, que estivessem sob bandeira portuguesa ou tivessem a nacionalidade desconhecida (Bill Palmerston); estivessem sob bandeira brasileira ou espanhola (Bill Aberdeen). Como os Estados Unidos não assinaram tratados de semelhante teor no período, embarcações registradas no país se tornaram algumas das poucas a ficarem resguardadas das inspeções britânicas (CONRAD, 1985, p. 149; HORNE, 2010, p. 55; MARQUES, 2016, p. 128).

Diante desta conjuntura, é possível crer que estadunidenses que, assim como John Smith Gillmer, já fossem inseridos na economia e na sociedade brasileira e/ou tivessem experiência com navegação transatlântica, vissem no contrabando negreiro uma possibilidade de investimento e de obtenção de lucros. No caso de Gillmer, um terceiro elemento favorecia seu ingresso no negócio: Baltimore, uma das regiões na qual ele atuava nos Estados Unidos, era a principal região produtora de barcos próprios para serem empregados no tráfico ilegal (GRADEN, 2007, p. 11; HORNE, 2010, p. 87; MARQUES, 2016, p. 130).

Mapear detalhadamente a participação de John Smith Gillmer no crime é uma tarefa difícil, visto que, por se tratar de uma atividade ilícita, uma expedição negreira realizada com sucesso nem sempre deixava vestígios. No entanto, embora as fontes existentes sobre o contrabando representem apenas uma pequena amostra do que foi sua verdadeira proporção, elas contêm indícios a partir dos quais é possível conhecer dimensões tanto do funcionamento deste crime quanto da atuação dos contrabandistas.

A documentação por nós consultada indica que a principal forma de participação de John Smith Gillmer no tráfico ilegal foi justamente pelo fornecimento de embarcações para realização de expedições negreiras. Em 1844, por exemplo, ele foi acusado por um marinheiro estadunidense de vender o brigue Glória, em Salvador, mesmo sabendo que este seria empregado no contrabando. O depoimento do marujo, realizado no 
consulado do Rio de Janeiro, foi encaminhado pelo Ministro dos Estados Unidos no Brasil, Henry Wise, ao Secretário de Estado James Buchanan. O relato chegou a ser publicado em um artigo no Boston Daily Atlas, em 20 de abril de 1845 - indicativo da grande proporção tomada pelo caso. Gillmer respondeu à acusação criticando as autoridades estadunidenses e negando sua ligação com o crime (GRADEN, 2007, p. 29). Não encontramos indícios de que ele tenha sofrido qualquer sanção pelo ocorrido.

Outro exemplo da atuação de John Smith Gillmer no fornecimento de embarcações a serem empregadas no tráfico ilegal aparece no mesmo período. Em 19 de janeiro de 1845, o patacho Esperança, da Praça da Bahia e de propriedade de Antonio Gomes dos Santos e Cia. (A. G. Santos e Cia.), foi preso pela corveta H. M. S. Larne por suspeita de envolvimento no crime. O patacho havia deixado Salvador um mês antes, em 19 de dezembro de 1844, carregado de aguardente, tabaco e fazendas (COMISSÃO..., 1860, p. 1).

A carta de ordens dava instruções para o capitão se dirigir a Onim (atual Lagos, na Nigéria), entregar parte do carregamento e tentar vender ("trocar por dinheiro") a outra parte. Não conseguindo realizar a segunda etapa da transação em Onim, este deveria seguir dali para outros portos até São Thomé, e trocar o restante da carga, preferencialmente, por ouro ou prata. Seu local de destino, uma das principais regiões de abastecimento do tráfico de escravos para a Bahia, assim como suas mercadorias, foram algumas das razões pelas quais, não sem objeções, o patacho foi condenado pela comissão-mista anglo-brasileira de Serra Leoa (COMISSÃO..., 1860, p. 1).

Ocorre que o Esperança não fora a primeira opção de navio da Antonio Gomes dos Santos e Cia. para a realização de sua expedição. Consta que os sócios da firma haviam tentado fretar com John Smith Gillmer uma das embarcações dos Estados Unidos que estavam a ele consignadas, buscando assim recorrer ao uso de "algum navio de mais insuspeita bandeira" para utilizarem na empreitada. Visto que não obtiveram êxito no fretamento com Gillmer, não restou alternativa à sociedade A. G. Santos e Cia. "senão arriscar a bandeira brasileira" (COMISSÃO..., 1860, p. 1).

Segundo Antônia Wright, a John Smith Gillmer e Cia. era a principal consignatária de navios negreiros na Bahia na década de 1840 (WRIGHT, 1978, p. 245). A empresa contava com uma rede de sócios e funcionários que incluía autoridades estadunidenses no Brasil, a exemplo do Cônsul dos Estados Unidos na Bahia, Alexander Tyler; do Cônsul dos Estados Unidos em Pernambuco, Joseph Ray; e G.R. Forster, que havia sido Cônsul dos Estados Unidos tanto em Pernambuco quanto na Bahia (WRIGHT, 1978, p. 245; MARQUES, 2016, p. 160).

O envolvimento de cônsules dos Estados Unidos em atividades comerciais, ainda que em firmas vinculadas a negócios ilícitos, como o tráfico ilegal, parece ter sido recorrente em diferentes partes do mundo. Isto porque, o caminho para a nomeação para um cargo diplomático passava, muitas vezes, pelas redes comerciais. De acordo com Stephen Chambers, era comum que negociantes se tornassem cônsules em algum ponto de sua trajetória. Ocupando estes cargos, eles agiam em favor dos interesses tanto de seu país quanto das firmas que representavam. Ademais, estes negociantes-diplomatas ${ }^{5}$ utilizavam seu posto político para obter vantagens mercantis, por exemplo, liberando embarcações apreendidas ou acessando informações privilegiadas nos

\footnotetext{
${ }^{5}$ O termo utilizado pelo autor é merchant-diplomats (CHAMBERS, 2017, p. 200-204).
} 
mercados. Na América, poderiam, entre outros, fazer vistas grossas ou agir em favor da continuidade do contrabando negreiro (CHAMBERS, 2017).

Neste sentido, um dos casos mais lembrados pela historiografia é o de William Wright, no Rio de Janeiro. Negociante estadunidense, envolvido no comércio entre Brasil e Estados Unidos, assim como Gillmer, Wright atuava na importação de farinha de trigo, na exportação de café e no contrabando negreiro. ${ }^{6}$ As evidências aqui apresentadas demonstram que a participação de autoridades e grandes negociantes dos Estados Unidos no tráfico ilegal para o Brasil também ocorria em outras províncias, havendo indícios de que estes grupos estavam interligados. Segundo Dale Graden, John Smith Gillmer, por exemplo, "mantinha estreitas ligações com conhecidos traficantes de Salvador e com casas comerciais no Rio de Janeiro ligadas ao tráfico negreiro, tais como Maxwell Wright e Companhia", firma da qual William Wright era sócio (GRADEN, 2007, p. 29).

Além de fornecer embarcações ao contrabando, John Smith Gillmer também organizava expedições negreiras. Para o período compreendido entre 1826 e 1849, mapeamos (a partir de periódicos disponíveis na Hemeroteca Digital da Fundação Biblioteca Nacional) 36 entradas de navios em portos brasileiros consignados a John Smith Gillmer, individualmente ou em sociedade. Destes, cinco (14,9\% aproximadamente) ingressaram "em lastro", isto é, sem mercadorias ou passageiros a bordo (todos no porto de Salvador): a barca Mauly, vinda de Buenos Aires (1835) (NOTÍCIAS..., 1835, p. 4); a galera James Perkins, vinda do Rio de Janeiro, (1841) (MOVIMENTO..., 1841a, p. 4); a escuna Platarch, vinda de Pernambuco (em 1843) (MOVIMENTO..., 1843c, p. 4); o brigue escuna Alberto, vindo de Onim (1845) (MOVIMENTO..., 1845, p. 4); e o patacho Bridgton, vindo de local não declarado (1848) (MOVIMENTO..., 1848, p. 4).

Analisados isoladamente, estes dados não fornecem grandes evidências da participação do negociante no contrabando. Quando pensados dentro do contexto de reorganização do tráfico transatlântico na ilicitude, no entanto, eles adquirem outro sentido. Como apontado por Pierre Verger, aquele foi um artifício recorrente entre os contrabandistas. O esquema (identificado por autoridades inglesas, por exemplo), funcionava da seguinte forma: ao deixarem os portos, os navios declaravam como local de destino áreas que não fossem regiões de aquisição de cativos, como a Ilha de Cabo Verde, ou mesmo portos ao longo do litoral brasileiro. Mas os percursos por eles realizados eram completamente diferentes (VERGER, 1987, p. 428).

Os comandantes os dirigiam à costa do continente africano e os abasteciam de indivíduos escravizados. No retorno ao Brasil, desembarcavam as cargas humanas em algum dos ancoradouros utilizados pelo contrabando negreiro após 1831, dando, por fim, entrada nos portos oficiais das províncias, afirmando estarem "em lastro". Como justificativa para a não apresentação de vistos oficiais relativos à viagem, os comandantes alegavam, por exemplo, que o trajeto não havia sido completado em virtude de imprevistos no caminho (VERGER, 1987, p. 428).

Os locais de origem daqueles navios, especialmente os da década de 1840, reforçam a tese de que eles estavam sendo empregados no contrabando negreiro. $A$ galera James Perkins e a escuna Platarch tiveram como local de partida declarado o Rio de Janeiro e Pernambuco, que, juntamente com a Bahia, eram as três principais

\footnotetext{
${ }^{6}$ Sobre a atuação de William Wright no Brasil, ver os trabalhos de Alan dos Santos Ribeiro (2014), Daniel Rood (2014), Gerald Horne (2010) e Leonardo Marques (2016).
} 
regiões de desembarque do tráfico transatlântico para o Brasil. Enquanto isso, o brigue escuna Alberto teve como origem o porto de Onim, no Golfo de Benim, uma das principais regiões de fornecimento de africanos escravizados para a Bahia. O patacho Bridgton, por sua vez, sequer teve a origem declarada. Estes casos indicam que, além de fretar e vender embarcações para os contrabandistas, o próprio Gillmer também era um deles.

Nota-se ainda que, excetuando-se os casos do Corporal Trim (1826) e do Rasselas (1828), o ano de ingresso no porto da Bahia dos cinco navios que declararam estar "em lastro" (iniciadas com a barca Mauly em 1835 e encerradas com o ingresso do patacho Bridgton em 1848) corresponde a um período muito próximo ao de maior regularidade das atividades de navegação de John Smith Gillmer, que vai de 1833 a 1849. Se, associado a isso, levarmos em consideração que aquelas entradas "em lastro" representam apenas um pequeno vestígio de sua ação no crime, constatamos que o negociante e, posteriormente, cônsul dos Estados Unidos no Brasil, participou ativamente do contrabando negreiro para o Império durante quase todo o período em que este vigorou.

Os casos dos brigues escunas Alberto e Washington's Barge, por exemplo, não só evidenciam a ação direta de John Smith Gillmer no tráfico ilegal, como apontam para os problemas daí decorrentes que ele teve que enfrentar. Em 1844, o negociante enviou dois carregamentos para a costa do continente africano, os brigues escunas estadunidenses Washington's Barge e Albert[o], tendo aquele saído do porto da Bahia no dia 4 de dezembro e este no dia 11 (MOVIMENTO..., 1844a, p. 4; MOVIMENTO..., 1844 b, p. 4). Ambos estavam carregados com tabaco, aguardente e fazendas, ou seja, mercadorias utilizadas no contrabando negreiro para aquisição de escravizados.

Segundo Dale Graden, lá chegando, o Washington's Barge foi vendido por seu comandante e sua tripulação retornou a Salvador a bordo do brigue Alberto, havendo suspeitas de que o Washington's Barge voltaria carregado de escravos para a Bahia (GRADEN, 2007, p. 28). Converge com as informações apresentadas pelo autor o fato de que mapeamos o ingresso do brigue Alberto no porto da Bahia, "em lastro", vindo de Onim, como anteriormente mencionado, em 23 de abril de 1845 (MOVIMENTO..., 1845, p. 4).

Em quatro de maio daquele ano, o cônsul estadunidense no Rio de Janeiro enviou uma correspondência diplomática ao seu congênere na Bahia, Alexander Tyler, acusando os cidadãos Jacob Woodburry e Thomas Duling, comandantes daquelas embarcações, de terem conduzido expedições negreiras para o continente africano. Tyler, então, determinou a prisão destes (GRADEN, 2007, p. 28).

Tendo seu encarceramento decretado, o comandante do Washington's Barge, Thomas Duling, tentou fugir. Seu plano era sair de Salvador com destino a Recife, de onde pegaria um segundo navio para a Filadélfia. Já a bordo da embarcação que o levaria para Pernambuco, pouco antes do início da viagem, Duling foi abordado pela polícia baiana e obrigado a desembarcar. Da mesma forma, Jacob Woodburry, comandante do Alberto, também foi detido, assim como toda a tripulação deste. Mas o grupo permaneceu pouco tempo na cadeia. Em sete de maio, eles foram liberados pelo chefe de polícia João Joaquim da Silva. Duling deixaria Salvador e partiria para os Estados Unidos nos dias seguintes à sua soltura, em 11 de maio. Enquanto isso, há indícios de que Woodburry tenha permanecido na Bahia (GRADEN, 2007, p. 28).

De acordo com Graden, o episódio gerou grande imbróglio entre Gillmer e as autoridades consulares estadunidenses na Bahia. Conforme o autor, a forma como as prisões de Dulling e Woodbury foram conduzidas e a exposição pública a que eles foram submetidos causaram indignação em John Smith Gillmer. O negociante chegou 
a enviar uma correspondência para o Secretário de Estado dos Estados Unidos, James Buchanan, no dia 10 de maio, queixando-se da atuação de Alexander Tyler. Na carta, Gillmer e outros quatro estadunidenses, George Carey, W. T. Harris, George Dunham e Joseph Ray, argumentaram que a crítica ao comportamento de Tyler se referia à forma como a prisão fora conduzida, e não como defesa da continuidade do contrabando negreiro, negócio que afirmavam abominar (GRADEN, 2007, p. 28-29).

Os detalhes apresentados por Dale Graden sobre o ocorrido são de extrema relevância para ratificar a participação direta de Gillmer no tráfico ilegal. O que Graden aparentemente desconhecia na elaboração de seu estudo é que o Washington's Barge e o Alberto estavam consignados a John Smith Gillmer e sócios. Além disso, pelo menos um dos negociantes que se queixaram ao Secretário de Estado dos Estados Unidos sobre as medidas consideradas arbitrárias de Alexander Tyler, Joseph Ray, era sócio de Gillmer; e o próprio Alexander Tyler era vinculado à firma John Smith Gillmer e Cia. (WRIGHT, 1978, p. 245; MARQUES, 2016, p. 160; GRADEN, 2007; HOWARD, 1963, p. 296). Neste sentido, ao fazerem a queixa, os negociantes deveriam estar muito mais movidos por interesses econômicos e pessoais do que por uma solidariedade entre irmãos estadunidenses, propriamente dita.

Vale dizer que, quando Henry Wise assumiu o cargo de Ministro dos Estados Unidos no Brasil, em 1844, ele teve em Alexander Tyler um dos primeiros alvos de sua campanha de repressão à participação de estadunidenses no contrabando negreiro. Em virtude da escancarada participação da John Smith Gillmer e Cia. no crime, exemplificada por meio dos episódios supramencionados, para assegurar seu posto de Cônsul dos Estados Unidos na Bahia, em 1845, Tyler foi obrigado por Henry Wise a se explicar e pedir demissão da firma (WRIGHT, 1978, p. 246; MARQUES, 2016, p. 160).

Entretanto, Alexander Tyler não foi capaz de se manter no cargo por muito tempo. Em 1848, três anos após os incidentes envolvendo os brigues escunas Washington's Barge e o Alberto, ele foi destituído do posto de Cônsul (GRADEN, 2007, p. 29).

\section{DE CONTRABANDISTA A CÔNSUL}

A partir de meados da década de 1840, provavelmente, auge da sua atuação no contrabando negreiro, além de ampliar sua participação no âmbito da navegação transatlântica, John Smith Gillmer começou a investir em outras atividades econômicas e a diversificar seus negócios. É possível crer que estes processos estiveram intimamente relacionados. Em virtude do caráter ilegal do tráfico transatlântico no período, a realização de novos investimentos permitia a Gillmer legitimar suas operações como negociante, camuflar sua participação no crime e abrir novas possibilidades de obtenção de lucros.

Em 1844, por exemplo, ele se uniu a dois outros negociantes na província da Bahia, também envolvidos no contrabando negreiro, Antonio Francisco de Lacerda e Antonio Pedrozo de Albuquerque, e juntos fundaram a fábrica têxtil Todos os Santos, maior do gênero no Império do Brasil durante todo o período em que esteve ativa, (SANTOS, 2020). Já em 1847, John Smith Gillmer foi sócio fundador, com outros importantes nomes no cenário baiano, como o próprio Antonio Francisco de Lacerda e o político Francisco Gonçalves Martins, da Companhia Bonfim de Navegação a Vapor (COMPANHIA..., 1847, p. 4); e eleito segundo secretário do Banco Comercial da Bahia, instituição intimamente ligada à Associação Comercial da província (REDACÇÃO, 1847, p. 3). 
Em 1850, Gillmer foi nomeado Cônsul dos Estados Unidos na Bahia. Mas, o que teria levado o governo estadunidense a indicar um agente do contrabando negreiro para o cargo? Quais interesses do país norte-americano se escondiam por trás desta designação? Estes arranjos ainda são desconhecidos por nós. Devem ter colaborado para isso sua profunda inserção na economia baiana, seus vínculos comerciais com agentes estadunidenses no Brasil, assim como as conexões que deveria possuir com seu país de origem, além do Rio da Prata e, por meio do contrabando negreiro, com o continente africano.

Em passagem pela Bahia, em meados da década de 1850, o missionário James Cooley Fletcher se hospedou na residência de John Smith Gillmer, em Salvador, e deixou registradas suas impressões sobre as redes nas quais ele estava envolvido. De acordo com Fletcher, devido à inserção do negociante na sociedade baiana, sua residência era muito bem frequentada e nela era possível encontrar com "brasileiros dos mais refinados e bem-educados". Ainda segundo o missionário, em virtude disso, nas semanas em que ficou hospedado com o Cônsul e sua família, teve oportunidade de estabelecer contato tanto com cidadãos da Bahia quanto com estrangeiros residentes em Salvador (KIDDER; FLETCHER, 1941, p. 209).

Como anteriormente mencionado, era comum que negociantes, notadamente os maiores e mais bem-sucedidos, chegassem a ocupar cargos políticos, inclusive, diplomáticos. Sócios do próprio John Smith Gillmer, como Alexander Tyler, Joseph Ray, e G.R. Forster, já haviam estado nesta posição. No entanto, chama atenção o fato de que, enquanto Alexander Tyler, por exemplo, sofreu repressão por estar associado a uma firma que agia no contrabando negreiro, Gillmer foi nomeado para cônsul apesar de sua atuação predecessora neste crime. Vale recordar que ambos haviam sido sócios na mesma firma, que levava o nome de ninguém menos que John Smith Gillmer.

Neste sentido, no que tange à sua participação no tráfico ilegal, a nomeação de Gillmer levanta a hipótese da existência de certa conivência dos Estados Unidos com este crime. Vale recordar que, mesmo após a promulgação da Lei Eusébio de Queirós, esforços para a realização de expedições negreiras para o Brasil continuaram a ser efetuados. Inclusive, a última tentativa de desembarque de africanos escravizados no litoral brasileiro de que se tem registro foi feita em uma embarcação construída nos Estados Unidos (ELTIS, s.d). Ademais, em perspectiva ampliada, o contrabando negreiro para Cuba, para o qual muitos agentes que atuavam no tráfico ilegal para o Brasil migraram a partir de 1850, esteve ativo até a segunda metade da década de 1860 (MARQUES, 2016).

Desta forma, é possível levantar uma hipótese, ainda por ser aprofundada, de que não fora a participação de Alexander Tyler no contrabando negreiro que provocou sua destituição do cargo de cônsul, mas sim sua atuação no combate a este crime. Como anteriormente mencionado, Tyler chegou a deixar a firma John Smith Gillmer e Cia. e sofreu queixas por parte da comunidade mercantil estadunidense em Salvador, inclusive de John Smith Gillmer, em virtude das medidas que adotou para coibir a participação de estadunidenses no tráfico ilegal para o Brasil. Neste sentido, a comunidade mercantil estadunidense na Bahia deve ter pressionado pela deposição de Alexander Tyler e fornecido suporte à nomeação de John Smith Gillmer para o cargo de cônsul, contando com a sua conivência para a continuidade do contrabando.

Aparentemente, após se tornar cônsul, John Smith Gillmer deixou de estar à frente de negócios de navegação transatlântica, ao menos na modalidade lícita, ou mesmo que tenha encerrado sua participação nesta atividade, visto que não localizamos 
registros de entradas ou saída de embarcações consignadas ao negociante, ou firmas que levassem seu nome, a partir de 1849, em portos brasileiros. Também não localizamos nenhum novo investimento realizado por ele a partir da década de 1850. É provável que, assim como Alexander Tyler, Gillmer tenha sido compelido pelo governo estadunidense a encerrar alguns de seus negócios, como as atividades da firma John Smith Gillmer e Cia., após sua designação para o cargo.

Desde então, além de suas atividades como cônsul, ele continuaria atuando na Associação Comercial da Bahia, tendo sido eleito membro da junta diretora desta entre os anos de 1854 e 1858 (COMPANHIAS..., 1854, p. 219; COMPANHIAS..., 1855, p. 254; COMPANHIAS..., 1857, p. 272; COMPANHIAS..., 1858, p. 267); como sócio da fábrica Todos os Santos, até 1860 (SANTOS, 2020, p. 201); como membro do Banco Comercial da Bahia e, a partir de 1853, membro da junta diretora da Caixa Filial do Banco do Brasil na Bahia (GAMBI, 2010); e membro da segunda Companhia Bahiana de Navegação a Vapor (produto da fusão das Companhias Bonfim e Santa Cruz de Navegação a Vapor) a partir de 1858 (SAMPAIO, 2006, p. 127).

Não sabemos se, quando John Smith Gillmer assumiu o posto de cônsul na Bahia, ele continuou fornecendo navios para as atividades residuais do contrabando negreiro, já que, se, de um lado, havia um histórico de participação dos cônsules estadunidenses no crime, de outro, a pressão dos ministros do país sobre o encerramento da participação destes no crime vinha se acirrando, como vimos no caso de Alexander Tyler. Além disso, o próprio empenho das autoridades brasileiras em combater o contrabando, após a promulgação da Lei Eusébio de Queirós, em 1850, se tornou mais efetivo.

De todo modo, é certo que, ocupando o cargo de cônsul nos Estados Unidos no Brasil em um período em que a repressão ao tráfico ilegal se intensificava, Gillmer experimentaria as pressões relativas ao posto. Já em 1850, ele se queixou dos protestos e oposição que sofria ao negar a concessão de cartas marítimas para embarcações estadunidenses cujo emprego, publicamente sabido, era o contrabando negreiro (CABAT, 1968, p. 335). Provavelmente, a oposição que dizia sofrer era comportamento muito próximo do que tivera na época em que Alexander Tyler fora cônsul na Bahia.

Caso curioso que explicita o lugar controverso ocupado por Gillmer naquela altura foi o do navio Bridgeton. Em 1850, já na condição de Cônsul, ele enviou uma carta ao então Secretário de Estado dos Estados Unidos, John M. Clayton, buscando saber quais os meios existentes para impedir o Bridgeton de navegar entre a Bahia e o continente africano ou forçá-lo a ir aos Estados Unidos para ser registrado. A razão disso era o conhecido emprego deste no contrabando negreiro. Ocorre que, como afirmou na correspondência, Gillmer fora o fornecedor do barco. Ele havia vendido em Salvador, em nove de novembro de 1849, o Bridgeton para o capitão Philip R. Stanhope, de Nova York. Ainda segundo ele, a embarcação havia recebido do cônsul que Ihe antecedeu a permissão para viajar para a África, o que Ihe impossibilitava de embargá-la (CABAT, 1968, p. 336).

Este episódio nos faz retornar ao caso do (quase) homônimo Bridgton, um dos navios consignados a John Smith Gillmer que deram entrada em portos brasileiros. O patacho, possivelmente empregado no tráfico ilegal, ingressou no porto da Bahia em lastro, sem origem declarada, em 1848 - portanto, um ano antes do negociante realizar a venda do Bridgeton para Philip R. Stanhope. Desta forma, é muito provável que o Bridgeton e o patacho Bridgton fossem a mesma embarcação. Gillmer, agora na posição de cônsul, vivia o ônus de sua participação no crime. O caso do Bridgton também nos leva a refletir até que ponto a atuação de Gillmer na repressão ao tráfico 
ilegal fora efetiva, visto que a ocupação do cargo de cônsul dos Estados Unidos poderia conflitar com seus interesses pessoais.

Quatro anos mais tarde, em 1856, quando da apreensão da escuna estadunidense Mary Smith, ${ }^{7}$ Gillmer já demonstrava ter (ou aparentar ter) uma posição dura com relação ao tráfico ilegal. Naquela ocasião, manifestou sua indignação sobre as precárias condições que a embarcação oferecia aos escravizados e recusou-se a prestar ajuda ao capitão desta, além de pedir investigação sobre a firma nova-iorquina envolvida com a expedição (CABAT, 1968, p. 344).

\section{CONSIDERAÇÕES FINAIS}

A participação de estadunidenses, bem como o emprego de embarcações e da bandeira do país no contrabando negreiro para o Brasil, é recorrente na historiografia sobre a temática, e vem sendo retomada nos últimos anos. Também tem sido alvo de estudos, a repressão feita pelo governo do país norte-americano às ações destes sujeitos, incluindo destituições de autoridades coniventes e prisão de indivíduos envolvidos com o crime.

O caso de John Smith Gillmer, aqui analisado, ajuda a exemplificar a complexidade deste processo. Os episódios mencionados, com a destituição de Alexander Tyler do cargo de cônsul e as prisões dos comandantes e das tripulações dos brigues Alberto e Washington's Barge indicam que houve, em alguma medida, a atuação estatal dos Estados Unidos no combate ao contrabando negreiro, especialmente a partir de meados da década de 1840. Por outro lado, e ao mesmo tempo, o país norte-americano não só puniu como também promoveu os indivíduos com sabida participação neste crime, como indica a nomeação de John Smith Gillmer para o cargo de cônsul.

John Smith Gillmer se inseriu na economia brasileira, provavelmente, na década de 1820, por intermédio do transporte marítimo de cargas e passageiros, primeiro pela navegação transatlântica entre o Brasil e os Estados Unidos e, posteriormente, por meio da navegação de cabotagem. Nas décadas de 1830 e, principalmente, na década de 1840, seus negócios passaram por processos de expansão e diversificação, possibilitados, entre outros fatores, pela sua participação no contrabando negreiro para o Brasil. Já envolvido com a navegação transatlântica e possuindo relações comerciais com o país, Gillmer se aproveitou da demanda gerada pelo tráfico ilegal por embarcações e pela bandeira dos Estados Unidos para fornecê-las aos contrabandistas, e até mesmo para fazer suas investidas diretas no negócio, organizando expedições.

A atuação de Gillmer no crime não passou despercebida. Ela fora alvo de denúncias e querelas, ganhando páginas nos jornais no Brasil e nos Estados Unidos. No entanto, apesar disso e de alguns de seus associados, como Alexander Tyler, sofrerem duras repressões do governo estadunidense, ele parece ter saído ileso das acusações que recebeu. Em 1850, possivelmente contando com o apoio da comunidade mercantil estadunidense na Bahia e de outros interessados na continuidade do contrabando, foi nomeado Cônsul dos Estados Unidos na província. A partir de então, teria que desempenhar um papel controverso: o de reprimir o crime para o qual tanto colaborou.

\footnotetext{
${ }^{7}$ A apreensão da escuna Mary Smith é um dos últimos registros conhecidos de tentativa de desembarque de africanos escravizados no Brasil (ELTIS, s. d).
} 


\section{REFERÊNCIAS}

ANNUNCIOS. Correio Mercantil, Bahia, v. 3, n. 527, 7 de agosto de 1838. Disponível em http://memoria.bn.br/DocReader/DocReader. aspx?bib=186244\&pesq=gillmer\&pasta=ano\%20183\&pagfis=379. Acesso em: 10 set. 2020.

AVISOS MARÍTIMOS. Correio Mercantil, Bahia, ano 8, n. 86, 24 abril 1841. Disponível em: http://memoria.bn.br/DocReader/DocReader. aspx ?bib=186244\&pesq=gillmer\&pasta=ano\%20184\&pagfis=3410. Acesso em: 20 set. 2020.

AVISOS MARÍTIMOS. Jornal do Commercio, Rio de Janeiro, ano 15, n. 45, 17 fevereiro 1840. Disponível em: http://memoria.bn.br/DocReader/DocReader. aspx?bib=364568_03\&pesq=gillmer\&pasta=ano\%20184\&pagfis=179. Acesso em: 10 set. 2020.

BAHIA. O Mercantil, Bahia, ano 2, n. 207, 20 setembro 1845.

Disponível em: http://memoria.bn.br/DocReader/DocReader.

aspx?bib=817325\&pesq=GILLMER\&pasta=ano\%20184\&pagfis=964. Acesso em: 11 set. 2020.

CABAT, Geoffrey Alan. O comércio de escravos no Brasil visto por funcionários diplomáticos americanos (1845-1857). Revista de História, São Paulo, v. 36, n. 74, p. 329-347, 1968. Disponível em: http://www.revistas.usp.br/revhistoria/article/ view/127378/124560. Acesso em: 3 abr. 2019.

CHAMBERS, Stephen. "No country but their counting-houses": The U.S.-Cuba-Baltic Circuit, 1809-1812. In: BECKERT, Sven. ROCKMAN, Seth. Slavery's Capitalism: A New History of American Economic Development. Philadelphia: University of Pennsylvania Press, 2017. p. 195-207.

COMISSÃO ANGLO-BRASILEIRA. Jornal do Commercio, Rio de Janeiro, ano 35, n. 74, 15 março 1860. Disponível em: http://memoria.bn.br/DocReader/DocReader. aspx?bib=364568_05\&pesq=GILLMER\&pasta=ano\%20186\&pagfis=298. Acesso em: 11 set. 2020 .

COMPANHIA BOM-FIM. Correio Mercantil, Bahia, ano 14, n. 24, 1 fevereiro 1847. Disponível em: http://memoria.bn.br/DocReader/DocReader. aspx?bib=186244\&pesq=GILLMER\&pasta=ano\%20184\&pagfis=6478. Acesso em: 11 set. 2020 .

COMPANHIAS, SOCIEDADES, AGÊNCIAS ETC. Almanak Administrativo, Mercantil, e Industrial da Bahia, para o anno de 1855. Ano 1. Bahia: Typ. de Camillo de Lellis Masson \& C., 1854. Disponível em: http://memoria.bn.br/DocReader/DocReader. aspx?bib=706825\&pesq=GILLMER\&pasta=ano\%20185\&pagfis=224. Acesso em: 11 set. 2020. 
COMPANHIAS, SOCIEDADES, AGÊNCIAS ETC. Almanak Administrativo, Mercantil, e Industrial da Bahia, para o anno de 1856. Ano 2. Bahia: Typ. de Camillo de Lellis Masson \& C., 1855. Disponível em: http://memoria.bn.br/DocReader/DocReader. aspx?bib=706825\&pesq=GILLMER\&pasta=ano\%20185\&pagfis=604. Acesso em: 11 set. 2020.

COMPANHIAS, SOCIEDADES, AGÊNCIAS ETC. Almanak Administrativo, Mercantil, e Industrial da Bahia, para o anno de 1857. Ano 3. Bahia: Typ. de Camillo de Lellis Masson \& C., 1857. Disponível em: http://memoria.bn.br/DocReader/DocReader. aspx?bib=706825\&pesq=GILLMER\&pasta=ano\%20185\&pagfis=1009. Acesso em: 11 set. 2020.

COMPANHIAS, SOCIEDADES, AGÊNCIAS ETC. Almanak Administrativo, Mercantil, e Industrial da Bahia, para o anno de 1858. Ano 4. Bahia: Typ. de Camillo de Lellis Masson \& C., 1858. Disponível em: http://memoria.bn.br/DocReader/DocReader. aspx?bib=706825\&pesq=GILLMER\&pasta=ano\%20185\&pagfis=1451. Acesso em: 11 set. 2020 .

CONRAD, Robert. Tumbeiros: o tráfico de escravos para o Brasil. São Paulo: Brasiliense, 1985.

DECLARAÇÕES. O Commercio, Bahia, n. 63, 20 março 1843.

Disponível em: http://memoria.bn.br/DocReader/DocReader.

aspx?bib=719110\&pesq=GILLMER\&pasta=ano\%20184\&pagfis=252. Acesso em: 11 set. 2020.

ELTIS, David (org.). The Transatlantic Slave Trade Database: voyages. Viagem 4968. Disponível em: https://www.slavevoyages.org/voyage/database. Acesso em: 13 ago. 2020.

GAMBI, Thiago Fontelas Rosado. O banco da Ordem: política e finanças no império brasileiro (1853-66). 2010. 526 p. Tese (Doutorado em História). Departamento de História, Universidade de São Paulo, São Paulo, 2010.

GRADEN, Dale T. O envolvimento dos Estados Unidos no comércio transatlântico de escravos para o Brasil, 1840-1858. Afro-Ásia, Salvador. n. 35, p. 9-35, 2007. Disponível em: https://portalseer.ufba.br/index.php/afroasia/article/view/21125/13713. Acesso em: 11 fev. 2020.

HORNE, Gerald. O sul mais distante: Brasil, os Estados Unidos e o tráfico de escravos africanos. São Paulo: Companhia das Letras, 2010.

HOWARD, Warren S. American Slavers and the Federal Law, 1837-1862. Berkeley: University of California Press, 1963.

KIDDER, Daniel P.; FLETCHER, James C. O Brasil e os brasileiros: esboço histórico e descritivo. $7^{\text {a }}$. ed. São Paulo: Companhia Editora Nacional, 1941. v. 2. 
LAURIE, Bruce. Working people of Philadelphia, 1800-1850. Philadelphia: Temple University Press, 1980.

MARQUES, Leonardo. The United States and the Transatlantic Slave Trade to the Americas, 1776-1867. New Haven: Yale University Press, 2016.

MESQUITA, João Marcos. O comércio ilegal de escravos no atlântico: a trajetória de Manoel Pinto da Fonseca, c.1831 - c.1850. 2019. 160 p. Dissertação (Mestrado em História). Departamento de História, Universidade Federal do Estado do Rio de Janeiro, Rio de Janeiro, 2019.

MOVIMENTO DO PORTO. Correio Mercantil, Bahia, ano 8, n. 138, 6 julho 1841a. Disponível em: http://memoria.bn.br/DocReader/DocReader. aspx?bib=186244\&pesq=GILLMER\&pasta=ano\%20184\&pagfis=3620. Acesso em: 11 set. 2020.

MOVIMENTO DO PORTO. Correio Mercantil, Bahia, ano 15, n. 255, 13 novembro 1848. Disponível em: http://memoria.bn.br/DocReader/DocReader. aspx?bib=186244\&pesq=GILLMER\&pasta=ano\%20184\&pagfis=8674. Acesso em: 11 set. 2020.

MOVIMENTO DO PORTO. O Commercio, Bahia, n. 9, 12 janeiro 1843a. Disponível em: http://memoria.bn.br/DocReader/DocReader. aspx?bib=719110\&pesq=GILLMER\&pasta=ano\%20184\&pagfis=40. Acesso em: 11 set. 2020.

MOVIMENTO DO PORTO. O Commercio, Bahia, n. 57, 13 março 1843b. http://memoria.bn.br/DocReader/DocReader. aspx?bib=719110\&pesq=GILLMER\&pasta=ano\%20184\&pagfis=228. Acesso em: 11 set. 2020.

MOVIMENTO DO PORTO. O Commercio, Bahia, n. 143, 4 julho 1843c. Disponível em: http://memoria.bn.br/DocReader/DocReader. aspx?bib=719110\&pesq=GILLMER\&pasta=ano\%20184\&pagfis=572. Acesso em: 11 set. 2020.

MOVIMENTO DO PORTO. O Commercio, Bahia, n. 191, 2 setembro 1843d. Disponível em: http://memoria.bn.br/DocReader/DocReader. aspx?bib=719110\&pesq=GILLMER\&pasta=ano\%20184\&pagfis=764. Acesso em: 11 set. 2020.

MOVIMENTO DO PORTO. Jornal do Commercio, Rio de Janeiro, ano 14, n. 85, 16 abril 1839a. Disponível em: http://memoria.bn.br/DocReader/DocReader. aspx?bib=364568_02\&pesq=gillmer\&pasta=ano\%20183\&pagfis=11170. Acesso em: 10 set. 2020 .

MOVIMENTO DO PORTO. Jornal do Commercio, Rio de Janeiro, ano 16, n. 16, 18 janeiro 1841b. Disponível em: http://memoria.bn.br/DocReader/DocReader. 
aspx?bib=364568_03\&pesq=gillmer\&pasta=ano\%20184\&pagfis=1432. Acesso em: 10 set. 2020.

MOVIMENTO DO PORTO. O Despertador, Rio de Janeiro, n. 257, 9 fevereiro 1839b. Disponível em: http://memoria.bn.br/DocReader/DocReader. aspx?bib=706701x\&pesq=gillmer\&pasta=ano\%20183\&pagfis=1052. Acesso em: 10 set. 2020.

MOVIMENTO DO PORTO. O Mercantil, Bahia, ano 1, n. 29, 4 dezembro 1844a. Disponível em: http://memoria.bn.br/DocReader/DocReader. aspx?bib=817325\&pesq=GILLMER\&pasta=ano\%20184\&pagfis=64. Acesso em: 11 set. 2020.

MOVIMENTO DO PORTO. O Mercantil, Bahia, ano 1, n. 35, 11 dezembro 1844b. Disponível em: http://memoria.bn.br/DocReader/DocReader. aspx?bib=817325\&pesq=GILLMER\&pasta=ano\%20184\&pagfis=88. Acesso em: 11 set. 2020.

MOVIMENTO DO PORTO. O Mercantil, Bahia, ano 2, n. 93, 25 abril 1845. Disponível em: http://memoria.bn.br/DocReader/DocReader. aspx?bib=817325\&pesq=GILLMER\&pasta=ano\%20184\&pagfis=504. Acesso em: 11 set. 2020.

MOVIMENTO DO PORTO. O Sete d'Abril, Rio de Janeiro, v. 1, n. 658, 7 janeiro 1839c. Disponível em: http://memoria.bn.br/DocReader/DocReader. aspx?bib=709476\&pesq=gillmer\&pasta=ano\%20183\&pagfis=2787. Acesso em: 10 set. 2020.

NEGOCIANTES DA BAHIA. Almanak Imperial do Commercio e das Corporações Civis e Militares do Império do Brasil. Ano 2. Rio de Janeiro: Pedro Plancher Seignot, 1829. Disponível em: http://memoria.bn.br/DocReader/DocReader. aspx?bib=706183\&pesq=GILLMER\&pasta=ano\%20182\&pagfis=193. Acesso em: 11 set. 2020 .

NOTÍCIAS MARÍTIMAS. Diário da Bahia, Bahia, n. 311, 28 junho 1833. Disponível em: http://memoria.bn.br/DocReader/DocReader. aspx?bib=815250\&Pesq=gillmer\&pagfis=16. Acesso em: 10 set. 2020 .

NOTÍCIAS MARÍTIMAS. Diário da Bahia, Bahia, n. 39, 18 fevereiro, 1835. Disponível em: http://memoria.bn.br/DocReader/DocReader. aspx?bib=815250\&Pesq=gillmer\&pagfis=20. Acesso em: 10 set. 2020 .

ODIN, Woodbridge. Carta ao Governo da Província da Bahia. Arquivo Público do Estado da Bahia. Seção Provincial. Série Governo da Província. Documentos avulsos. Correspondência recebida do Consulado dos Estados Unidos (1811-1875). Maço 1177. 24 jul. 1826. 
ODIN, Woodbridge. Carta ao Governo da Província da Bahia. Arquivo Público do Estado da Bahia. Seção Provincial. Série Governo da Província. Documentos avulsos. Correspondência recebida do Consulado dos Estados Unidos (1811-1875). Maço 1177. 3 mar. 1828.

OLIVEIRA, Waldir Freitas. A industrial cidade de Valença: um surto de industrialização na Bahia no Século XIX. Salvador: Universidade Federal da Bahia, 1985.

PARTE COMERCIAL. Correio Mercantil, Bahia, ano 10, n. 202, 18 setembro 1843. Disponível em: http://memoria.bn.br/DocReader/DocReader. aspx?bib=186244\&pesq=GILLMER\&pasta=ano\%20184\&pagfis=4972. Acesso em: 11 set. 2020.

PARTE COMERCIAL. Correio Mercantil, Bahia, ano 11, n. 200, 19 setembro 1844. Disponível em: http://memoria.bn.br/DocReader/DocReader. aspx?bib=186244\&pesq=GILLMER\&pasta=ano\%20184\&pagfis=6070. Acesso em: 11 set. 2020.

PARTE COMERCIAL. Jornal do Commercio, Rio de Janeiro, ano 13, n. 244, 31 outubro 1838. Disponível em: http://memoria.bn.br/DocReader/DocReader. aspx?bib=364568_02\&pesq=gillmer\&pasta=ano\%20183\&pagfis=10633. Acesso em: 10 set. 2020.

PARTE COMERCIAL. Jornal do Commercio, Rio de Janeiro, ano 14, n. 7, 9 janeiro de 1839a. Disponível em: http://memoria.bn.br/DocReader/DocReader. aspx?bib=364568_02\&pesq=gillmer\&pasta=ano\%20183\&pagfis=10857. Acesso em: 10 set. 2020.

PARTE COMERCIAL. Jornal do Commercio, Rio de Janeiro, ano 14 n. 27, 1 fevereiro de 1839b. Disponível em: http://memoria.bn.br/DocReader/DocReader. aspx?bib=364568_02\&pesq=gillmer\&pasta=ano\%20183\&pagfis=10937. Acesso em: 10 set. 2020 .

PARTE COMERCIAL. O Despertador, Rio de Janeiro, n. 318, 26 abril 1839c. Disponível em: http://memoria.bn.br/DocReader/DocReader. aspx?bib=706701x\&pesq=gillmer\&pasta=ano\%20183\&pagfis=1297. Acesso em: 10 set. 2020.

REDACÇÃO. Correio Mercantil, Bahia, ano 14, n. 178, 3 agosto 1847. p. 3. Disponível em: http://memoria.bn.br/DocReader/DocReader. aspx?bib=186244\&pesq=GILLMER\&pasta=ano\%20184\&pagfis=7099. Acesso em: 11 set. 2020.

RIBEIRO, Alan dos Santos. "The leading comission-house of Rio de Janeiro": A firma Maxwell, Wright \& C.o. no comércio do Império do Brasil (c.1827-c.1850). 2014. 172 p. Dissertação (Mestrado em História). Departamento de História, Universidade Federal Fluminense, Niterói, 2014. 
ROOD, Daniel. Bogs of Death: Slavery, the Brazilian Flour Trade, and the Mystery of the Vanishing Millpond in Antebellum Virginia. The Journal of American History, Bloomington. v. 101, p. 19-43, jun. 2014. Disponível em: https://academic.oup.com/ jah/article-abstract/101/1/19/749115?redirectedFrom=PDF. Acesso em: 2 abr. 2019.

SAMPAIO, Marcos Guedes Vaz. Uma contribuição à história dos transportes no Brasil: a Companhia Bahiana de Navegação a Vapor (1839-1894). 2006. 341 p. Tese (Doutorado em História). Departamento de História, Universidade de São Paulo, São Paulo, 2006.

SANTOS, Silvana Andrade dos. Escravidão, tráfico e indústria na Bahia oitocentista: a sociedade Lacerda e Cia e a fábrica têxtil Todos os Santos. 2020. 269 p. Tese (Doutorado em História). Instituto de História, Universidade Federal Fluminense, Niterói, 2020.

WRIGHT, Antônia Fernanda Pacca de Almeida. Desafio americano à preponderância britânica no Brasil: 1808-1850. São Paulo; Brasília: Ed. Nacional; INL, 1978.

VALENCIA VILLA, Carlos Eduardo. Fluxos de mercadorias entre o Rio de Janeiro e a Virgínia em meados do século XIX. História Econômica \& História de Empresas, São Paulo, v. 17, n. 2, p. 415-441, 2014.

VERGER, Pierre. Fluxo e refluxo do tráfico de escravos entre o Golfo de Benim e a Bahia de Todos os Santos: dos séculos XVII a XIX. São Paulo: Corrupio, 1987.

\section{NOTAS}

\section{AUTORIA}

Silvana Andrade dos Santos: Doutora. Pesquisadora autônoma, Rio de Janeiro, RJ, Brasil.

\section{ENDEREÇO PARA CORRESPONDÊNCIA}

Rua Riachuelo, 148, ap. 1004, Centro, 20230-014, Rio de Janeiro, RJ, Brasil.

\section{ORIGEM DO ARTIGO}

Extraído da tese - Escravidão, tráfico e indústria na Bahia oitocentista: a sociedade Lacerda e Cia e a fábrica têxtil Todos os Santos (c.1844-c.1878), apresentada ao Programa de Pós-graduação em História Social da Universidade Federal Fluminense, em 2020.

\section{AGRADECIMENTOS}

Agradeço a Edilson Nunes dos Santos Júnior e a João Marcos Mesquita pela leitura e comentários.

\section{FINANCIAMENTO}

Esta pesquisa contou com financiamento do Conselho Nacional de Desenvolvimento Científico e Tecnológico (CNPq)

\section{APROVAÇÃO DE COMITÊ DE ÉTICA EM PESQUISA}

Não se aplica

\section{CONFLITO DE INTERESSES}

Não se aplica 


\section{LICENÇA DE USO}

Este artigo está licenciado sob a Licença Creative Commons CC-BY. Com essa licença você pode compartilhar, adaptar e criar para qualquer fim, desde que atribua a autoria da obra.

\section{PUBLISHER}

Universidade Federal de Santa Catarina. Programa de Pós-Graduação em História. Portal de Periódicos UFSC. As ideias expressadas neste artigo são de responsabilidade de seus autores, não representando, necessariamente, a opinião dos editores ou da universidade.

\section{EDITORES}

Flávia Florentino Varella (Editora-chefe)

Tiago Kramer de Oliveira

Waldomiro Lourenço da Silva Júnior

\section{HISTÓRICO}

Recebido em: 19 de maio de 2020

Aprovado em: 2 de agosto de 2020

Como citar: SANTOS, Silvana Andrade dos. Do contrabando ao consulado: a atuação do estadunidense John Smith Gillmer na Bahia (1826-1862). Esboços, Florianópolis, v. 27, n. 46, p. 534-553, set./dez. 2020. 